\title{
La experiencia estética como Ereignis. Significatividad y sentido en la relación con la obra de arte.
}

The aesthetic experience like Ereignis. Significance and meaning in relation to the work of art.

DOI: $10.32870 /$ sincronia.axxv.n79.29a21

\author{
Santiago Bellocq \\ Consejo Nacional de Investigaciones Científicas y Técnicas. Academia Nacional de Ciencias de \\ Buenos Aires (ARGENTINA) \\ CE: santiglm@hotmail.com
}

\section{Esta obra está bajo una Licencia Creative Commons Atribución-NoComercial 4.0 Internacional}

Recibido: $18 / 03 / 2020$

Revisado: 03/10/2020

Aprobado: $12 / 11 / 2020$

\section{RESUMEN}

El siguiente trabajo busca explicitar los elementos que aparecen en El origen de la obra de arte que permiten pensar la relación con las obras de arte desde una óptica estéticosemiótica -en línea con las investigaciones y el enfoque realizado por Adrián Bertorello-, teniendo en cuenta las nociones de mundo, significación y Ereignis para plantear así una "estética" no metafísica que se inserte en la crucial cuestión del destino del Dasein y su relación con la Verdad del ser, tomando como centro la fundación acontecial del sentido que se "transpropia" a él y que abre a una experiencia semántica en el arte.

Palabras Clave: E Heidegger. Experiencia estética. Significatividad. Ereignis.

\section{ABSTRACT}

The following work develops the elements that appear in The origin of the work of art that allow to think the relationship with the artworks from an aesthetic-semiotic approach -in line with the 
researches and the perspectives held by Adrián Bertorello-, taking in consideration the notions of world, signification and Ereignis in order to propose a non-metaphysical "aesthetic" that may be inserted in the crucial matter of the destiny of the Dasein and its connection with the Truth of Being, focusing in the evenemential foundation of meaning that "trans-propriates" to it leading to a semantic experience with the art.

Keywords: Heidegger. Aesthetic experience. Significatividad. Ereignis.

\section{Introducción}

Generalmente se suele decir que la cuestión del arte en Heidegger se ve reducida (sin perder por ello la increíble profundidad que alcanza) a una ontología de la obra de arte en la que, independientemente de qué tan coherente o interesante resulte, el "enigma del arte" transita una senda que desemboca en una filosofía del arte que no posibilita una estética. El mismo Heidegger advierte sobre el peligro de reducir la obra de arte a mero "objeto" para un sujeto; en efecto, la estética tradicional en tanto disciplina nacida en plena modernidad concibe la obra como ese objeto que es apercibido por la aísthesis, la percepción sensible humana. Esto dado a la sensibilidad, quizás procesado mediante algún juicio estético reflexionante, sumado a la misma capacidad de imaginación, derivaba en una vivencia (Erlebniss) subjetiva que debería darnos la pauta de lo que es la esencia del arte. Estas vivencias no sólo acreditarían lo que compete a las normas sobre gusto y deleite artístico, sino también las normas que deben configurar la producción artística en sí misma. Así, en pleno auge del subjetivismo moderno, todo remite a una vivencia; pero, como dice nuestro autor, "quizás sea la vivencia el elemento en que muere el arte" (Heidegger, 1935, p. 57). ${ }^{1}$

El entero pensamiento de Heidegger busca superar las categorías metafísicas tradicionales, superar el "olvido del ser", para pensar la "pregunta más digna de ser pensada". La metafísica, en

\footnotetext{
${ }^{1}$ Por motivos que luego indicaré, se usará también la primera versión de ese texto que data de 1931, hasta hace poco inédita, y que ha sido traducida por Ángel Xolocotzi en Revista de Filosofía $N^{\circ} 115$, año 38, México, Universidad Iberoamericana, versión digital. Para su distinción, se aclarará qué versión se utiliza mediante la indicación de sus años, 1931 o 1935.
} 
efecto, que comienza propiamente con la filosofía platónico-aristotélica, es básicamente la historia del olvido del ser en tanto se lo ha pensado como ente. Esta visión estática y ciertamente reductora es la base de prácticamente todas las filosofías actuales, que no conocen ni preguntar por el sentido del ser, sino que simplemente plantean diversas "cosmovisiones". Toda la filosofía actual se vería enmarcada en este abandono, por lo que naturalmente toda filosofía del arte también se ocuparía de la relación con las obras en tanto entes-objetos y no desde la relación entre el hombre y el ser, que es la gran cuestión de fondo. Por ello es que Heidegger busca emplear una terminología radicalmente nueva, realizando una apropiación muy particular del método fenomenológico de Husserl, para pensar la obra de arte desde un plano más "originario".

Así es que rechaza las categorizaciones heredadas del tiempo de Aristóteles que "explican" las obras (y los entes en general) desde el hylemorfismo así como rechaza también la dualidad sujeto-objeto, tan explotada como patentemente hueca. Su estilo, fuertemente criticado por una gran parte de la comunidad filosófica, generó en otros un real entusiasmo por pensar desde otros planos distintos de la ya agotada metafísica de la subjetividad. El origen de la obra de arte suscitó un sinnúmero de estudios sobre el ser de las obras, la esencia del arte, la verdad que ahí acontece; sin embargo, como señalé anteriormente, por lo general se han abocado a desarrollar las líneas abiertas por esta ontología de las obras, y no tanto la relación que cada Dasein puede tener con ellas. Lo que comúnmente se llama "experiencia estética" no recibe ningún tipo de tratamiento, quizás seguramente por el rechazo de Heidegger de la estética (siempre teniendo en cuenta que se remite a una disciplina metafísica, y por lo tanto que debe ser superada), aunque haya ciertos elementos implícitos que, según mi opinión, sí pueden ser abordados desde otro enfoque independiente de la "mera" sensibilidad (si es que esto existe monádicamente).

El siguiente trabajo busca explicitar los elementos que aparecen en El origen de la obra de arte que permitan pensar esta relación con las obras de arte desde otro ámbito, en este caso, desde una óptica estético-semiótica -en línea con las investigaciones y el enfoque realizado por Adrián Bertorello (Cfr. Bertorello, 2008)-, teniendo en cuenta las nociones de mundo-significación-Ereignis 
para plantear así una "estética" no metafísica que se inserte en la crucial cuestión del destino del Dasein y la posibilidad de su existencia auténtica en relación con la Verdad del ser.

\section{Mundo y sentido en Ser y Tiempo}

Es necesario, para transitar con propiedad el camino que seguiremos en torno a la relación con la obra de arte, remitirnos inicialmente a la noción de mundo que Heidegger acuñó, en parte tomado de Husserl, en parte desarrollado desde sus lecciones tempranas hasta su confección en Ser y Tiempo $^{2}$ donde por primera vez alcanza a ocupar un lugar determinante en la pregunta por el sentido del ser. Como sabemos, la obra entera busca responder esa pregunta; sin embargo, es altamente probable que a los lectores que lo abordan por primera vez se les pase de largo que ya al comienzo, en el parágrafo 2 , esa pregunta recibe un primer esbozo de respuesta: "[...] el ser, aquello que determina a los entes en cuanto entes, aquello 'sobre lo cual' los entes, como quiera que se los dilucide, son en cada caso ya comprendidos" (Heidegger, 2014, p. 15). ${ }^{3}$ Esta proposición acuerda casi perfectamente con la noción de mundo, definitoria de la misma constitución existenciaria del Dasein. La pregunta por el sentido del ser se pregunta desde el ser del Dasein, en tanto es el único ente "al que le va su ser". La existencia propia (o impropia) del Dasein está íntimamente afectada por su relación con el ser, en tanto horizonte de inteligibilidad donde aparecen los entes "intramundanos".

Mundo, en efecto, no es la totalidad de los entes del universo. Heidegger distingue entre dos sentidos ónticos y dos ontológicos de mundo, siendo el utilizado para su análisis existenciario aquel que piensa el mundo como "mundanidad", una estructura intencional del Dasein. Éste "abre el mundo" en tanto es su "ahí", donde se presentan los entes en dos modalidades: o como ser-antelos-ojos, o como ser-a-la-mano. En realidad, son dos aspectos sobre un mismo ente, que cambian de acuerdo al modo de presentación/comparecimiento de este frente al Dasein. En SuZ, sin embargo, es el ser-a-la-mano, el útil, el que deviene modelo para pensar la relación significativa con

\footnotetext{
2 En adelante "SuZ"

${ }^{3}$ El subrayado es mío.
} 
los entes y del mundo mismo. Todo útil implica necesariamente una referencia a un sistema articulado de referencias, siempre en relación con otros seres-a-la-mano, tensionados comprensivamente hacia un "para". Así, el ser del útil consiste en su referencia a esta totalidad.

Esta totalidad, desde la óptica del Dasein, se traduce en la conformidad que remite al "pormor-de-qué", la instancia final-práctica, auto-fundada, horizonte de todas las remisiones de los útiles y fundamento de inteligibilidad. Es el por-mor-de-qué el que abre un espacio de sentido, y eso será el mundo: un espacio de sentido estructurado por la significatividad. Esta disposición de los entes que se manifiestan en un horizonte de comprensión es lo propio de la mundanidad del mundo, que se proyecta originariamente desde el Dasein mismo en tanto es él quien abre el espacio. Toda relación indicada en este "estado de abierto" implica este comprender originario, y desde él es que todas las relaciones del referir son un "significar": así, la significatividad

[...] alberga en sí la condición ontológica de la posibilidad de que el 'ser ahí que comprende pueda, como 'ser-ahí' que interpreta, abrir lo que se dicen 'significaciones' que por su parte fundan el posible ser de la palabra y del lenguaje. La significatividad abierta es, en cuanto estructura existenciaria del 'ser-ahí', de su 'ser en el mundo', la condición óntica de la posibilidad del descubrimiento de una totalidad de conformidad. (p. 102)

Si recordamos lo citado anteriormente como primera aproximación al sentido del ser, eso "sobre lo cual" los entes son determinados (como ante-los-ojos o como a-la-mano) y comprendidos, podemos pensar con razón que en Heidegger el ser mismo es el mundo, en tanto espacio de sentido. Puede ser útil pensarlo análogamente como la función significante de Greimas, aquello que instituye el vínculo entre significado y significante.

Es importante tener todo esto en cuenta al abordar El origen de la obra de arte, donde la noción de mundo se ve "desplazada" sutilmente, cuando ya no sea tanto el Dasein el centro de este espacio, sino que su eje se descentrará tomando como instancia fundamental la obra misma. 


\section{La lucha por el sentido en la obra de arte}

El origen de la obra de arte fue inicialmente escrito en 1931 aunque no fue presentado hasta 19351936, en el marco de unas conferencias donde Heidegger lo reformuló. Si bien es un texto ya influido por la Kehre, notoria desde De la esencia de la verdad, esta primera versión sobre todo mantiene un estilo y unos rasgos que la hacen más cercana al período fenomenológico del así llamado "primer Heidegger". Esta primera versión es notablemente más breve y concreta que la posteriormente publicada, aunque no por ellos menos profunda; de hecho, su mayor claridad expositiva ayuda a entender una gran cantidad de cuestiones que en el texto de 1935 quedan oscurecidos por ese plus de argumentaciones poéticas que fueron, para algunos, aparentemente muy chocantes.

Dividido solo en dos partes, comienza también desechando la idea de pensar la obra desde la mera vivencia; propone pensar la obra de arte desde su carácter de cosa-obra. Es importante destacar que Heidegger está pensando siempre en "el gran arte", lo cual supone un gran interrogante de a qué se refiere; naturalmente al arte clásico-romántico, pero ¿no puede extenderse su reflexión también a otros tipos de arte más contemporáneos? En principio, abarca las obras que han sido conservadas y dispuestas en contextos espacio-temporalmente distintos de aquellos donde surgió. En ese sentido, se las "ha sacado fuera de su mundo"; veremos qué implicancia tiene esto posteriormente. Para empezar, hay algo en su ser-obra que se ha perdido. Esto implica que la obra quiere ser patente y pública de algún modo, en tanto "hace efecto" destacándose hacia lo abierto. La obra, por sí misma, está a la obra, en su exposición. Esto no refiere al hecho de ser expuesta en un museo o en una muestra determinada, sino que constituye una erección, que es a la vez consagración y glorificación. Heidegger señala que, en su consagración, la obra es una ofrenda, un don, que abre el espacio de lo sagrado. Ahí es donde el dios "es impulsado hacia lo abierto de su presencia", que conlleva la glorificación en tanto reconocimiento de "la dignidad y esplendor del dios". Es cierto que el estilo heideggeriano resulta altamente ambiguo, sobre todo en estos recursos poéticos, lo que da sostén a interpretaciones muy diversas. Sin embargo, quizás una clave interpretativa esté dada unas líneas más abajo: "toda exposición en 
el sentido de la erección consagrante-glorificante es siempre también levantamiento en cuanto un tipo de colocación de la construcción y de la estatua, en cuanto decir y nombrar dentro de un lenguaje" (Heidegger, 1931 p. 9). ${ }^{4}$ Quizás este "espacio de lo sagrado" sea más bien ese área semántica de significaciones advenientes, que traen el "esplendor"/claridad de un sentido nuevo donado por la misma obra.

En efecto, aquí es donde aparece la noción de mundo, ya que "la obra es en sí un alzarse en donde se rompe un mundo y en cuanto abierto es puesto en la permanencia"; el mundo no es, como ya vimos, la totalidad de los entes del cosmos, sino que es una especie de "séquito" que acompaña al Dasein y desde el cual se orienta todo ente emergente: "el mundo mundea". Esta mundanidad jamás puede ser concebida como objeto para una conciencia, sino que "señalando mantiene removido nuestro hacer y dejar en un ensamblaje de remisiones desde las cuales llega y se ausenta ${ }^{5}$ la benevolencia guiñante y la fatalidad golpeante de los dioses". Este mundo abierto por la obra, como estructura significativa, acontece no tanto en la obra misma sino en el Dasein; y esto, naturalmente, no puede darse sin al menos cierta transformación del mismo. La obra expone un mundo, es decir, un plexo de significaciones y referencias que revoluciona el campo semántico del ser-ahí. En ese sentido, el criterio para determinar el valor de una obra como obra de arte, mismo para delimitar el "gran arte", es este rasgo esencial de la exposición de un mundo; si esto no acontece, "no es una obra de arte, sino que es una pieza de arte que está a la obra en nada, solamente exhibe un poder vacío y quizás incluso causa alguna 'impresión'”. Heidegger critica esa postura que coloca la intensidad de la vivencia que uno siente al contemplar una obra en el más alto lugar, cuando en realidad de lo que se trata es de una experiencia de sentido profundo que debe afectar la propia relación del Dasein con el ser. Desde esta última aseveración es posible abrir el campo de juego de lo que incluiría el "gran arte", relativizándolo hacia una experiencia que no se queda en la sensibilidad del momento, sino que implica una transformación del mundo. Obra un "rechazo superior" de lo usual, de lo cotidiano, que puede asemejarse a la función poética de los

\footnotetext{
${ }^{4}$ El subrayado es mío.

${ }^{5}$ Recordemos que la presentación-sustracción es la dinámica misma del ser, que se muestra y se oculta.
} 
formalistas rusos, donde lo corriente se rompe y se oscurece forzando a la demora y la profundización de lo dado. La obra entonces crea el espacio semántico que ella domina y articula, alzando por ella misma, pero a través del Dasein un mundo. Esta participación del Dasein en la puesta-a-la-obra de la obra será crucial, como veremos más adelante. ${ }^{6}$

Además de la exposición, al ser-obra de la obra pertenece la composición. Heidegger ya había indicado que no podía pensarse el ser de la obra desde su ser-creado por un artista; eso podía llegar a desarrollarse fácilmente desde el modelo materia-forma predominante en la estética metafísica ya desde Platón y Aristóteles, pero condenándose así a la falta de fundamento y profundidad del otro pensar. Antes bien, Heidegger indica que el ser-obra de la obra es literalmente com-ponente. Esto que es compuesto es lo que llama la tierra, "aquello que despliega la plenitud constante y sin embargo retoma para sí lo desplegado y lo retiene" (1931, p.11). La esencia de la tierra es su cerrarse en lo abierto por el mundo; no es la mera materialidad de la obra, sino la esencial indeterminación del plano de la expresión, es decir, del elemento sensible que compone precisamente la obra. La obra no posee la tierra como causa material, sino que la "soporta" en sí, colocándose ella misma en la tierra como en su fundamento-desfondado, en ese abismo de la opacidad constitutiva de la expresión sensible pura. Esta composición, en tanto Herstellung, es una "producción", aquello donde se emplaza el mundo, la procedencia latente del sentido. Ahora bien, ¿qué relación guardan entre sí mundo y tierra?

Heidegger muestra que entre ellos hay una correlación esencial que determina el rasgo fundamental y propio del ser-obra de la obra: es el pólemos, la lucha entre ambas dimensiones, el ser de la obra. El mundo no tolera nada cerrado, la tierra por su parte se cierra constantemente resistiéndose a entrar en el claro de lo abierto por el mundo. ¿Cómo se da esto?

En cuanto la obra es disputa, entonces remueve a la tierra, abriéndola, en un mundo. Éste mismo como séquito señalante nunca se mueve hacia dentro de la tierra. Pero este

\footnotetext{
${ }^{6}$ Es cierto que puede verse en el pensamiento de Heidegger un corrimiento donde se comienza con una "subjetividad" (haciendo las gigantescas salvedades correspondientes) que organiza el plexo de referencias y se conduce a un descentramiento donde es la cosa misma la que articula el espacio semántico, signo de la "muerte del sujeto" que habita fecundamente toda su filosofía.
} 
movido removimiento mueve hacia delante la obra e inaugura algo abierto. Eso es el centro del espacio en donde la tierra está mundanamente cerrada y el mundo está terrenamente abierto. Es la obra la que funda apenas este espacio al abrirlo. Este espacio es la apertura del ahí, en el cual las cosas y los seres humanos llegan a pararse, para resistirlo (1931: 12). ${ }^{7}$

Vemos que hay una tensión permanente, un sostenimiento de la contradicción, que puede pensarse como el mismo enfrentamiento que ocurre entre los planos de la significación y del contenido del signo: hay un intento de clarificación, de estructurar lo esencialmente inestructurable mediante un sentido, resultando en un esfuerzo permanente por comprehender lo abismal de la sensibilidad cruda. Sin embargo, estas fuerzas en pugna delimitan el espacio semántico, los límites del claro donde el ente se manifiesta. $Y$ ahí es donde se introduce el Dasein, quien, demorándose en la obra, la resiste en su propia proyección comprensora, en tanto "ahí" del mundo abierto.

La obra de arte articula así el plexo de referencias ubicándose como su centro de orientación; tal es la fuerza de la obra, "norma del ente y del no-ente" ${ }^{8}$. Es necesario ver qué es lo que acontece en ese espacio abierto, y cómo el Dasein se pueda ver involucrado ahí.

\section{El acontecimiento de verdad en el arte como transpropiación de sentido}

Vimos que la obra abre el "ahí", el centro de lo abierto en tanto horizonte de inteligibilidad [¿̇er?] donde el ente aparece como tal. Esto que acontece en este espacio es lo que Heidegger llama verdad-que poco tiene que ver con una visión técnico-calculadora que la piensa como adecuaciónque hunde sus raíces en la noción griega de alétheia. La verdad es el acontecer fundamental de la inauguración de la apertura del ente, funda sentidos nuevos, abre pragmáticamente nuevas referencialidades; "la puesta-en-obra de la verdad, esa es la esencia del arte” (1931, p. 16). Esta verdad no es algo que exista previamente a la obra, sino que acontece al surgir la misma, en el

\footnotetext{
${ }^{7}$ El subrayado es mío.

8 "La obra de arte no sólo es obra porque es producida y hecha, sino porque e-fectúa el ser en un ente [...]. Gracias a la obra de arte, entendida como el ser que es en tanto ente, todo lo demás que aparece y que se puede hallar llega a confirmarse, a ser accesible, interpretable e inteligible como ente o como no-ente" (Heidegger, 2003 p. 147).
} 
momento de la apertura del mundo; no estamos en el reino de las verdades eternas, fuertes, sino en verdades relativas (al Dasein) que "deben llegar a ser", esencialmente dinámicas y contingentes. Como señalamos anteriormente, el mismo mundo, la verdad que alguna vez abrieron ciertas obras, puede decaer; Heidegger indica que "la privación de mundo y la decadencia de mundo es algo irreversible" (p. 7); lo mismo ocurre con el ser, que acontece epocalmente iluminando de maneras radicalmente distintas a los entes que en él se manifiestan, pero que eventualmente su donación puede (y probablemente va a) extinguirse.

Esta apertura del ente, dice Heidegger, acontece al ser proyectada, "poetizada"; para el autor, "todo arte es en esencia poesía" en la medida en que lo que en ella se manifiesta es diferente a como comúnmente es (la función poética del lenguaje, como vimos antes). Sólo en un proyecto, como horizonte de comprensión, es que puede ser inteligible (es decir, ser) el ente. Esta esencialidad poética no refiere a la poesía como disciplina artística singular (aunque la tiene en la más alta estima), sino que remite al lenguaje como el plano donde todo arte acontece. La esencia del lenguaje es elevar el ente a lo abierto en el claro de la verdad acontecida, es la estructura que significa la expresión de la obra misma. El lenguaje como poesía "nombras las cosas por primera vez", trae el ente a la palabra y al aparecer. A su vez, este decir es un proyectar donde "se anuncia como qué está abierto el ente", es decir, no crea al ente, pero sí lo define en su modalidad esencial. La poesía es entonces la esencia del lenguaje, y solo consecuentemente puede ser "expresión" de algo, en el sentido corriente; "el arte y la obra de arte no son una especie de lenguaje, sino viceversa: la obra lingüística es la figura fundamental del arte, ya que ésta es poesía": así, "en el decir poético siquiera lo abierto, en donde el ente como ente llega al despliegue y conservación, es proyectado y llegar a ser propiedad para el Dasein humano" (p. 18).9 ¿Qué significa este "Ilegar a ser propiedad" del Dasein?

La obra de arte, en tanto puesta-en-obra de la verdad, abre un mundo, un claro de inteligibilidad determinado y particular, que en tanto articulado como lenguaje es estructuralmente un espacio de significación que "dona" el ser, es decir, el sentido. Esto es lo que Heidegger llama

\footnotetext{
${ }^{9}$ El subrayado es mío.
} 
Ereignis, y que puede pensarse como un acontecimiento (de) [trans]-propiación de sentido ${ }^{10}$, donde Dasein y ser se apropian/expropian mutuamente del significado proyectado en ese espacio semántico entrecruzado por los dos mundos abiertos (en este caso, del Dasein y de la obra de arte), comprometiéndose esencialmente en una relación ontológica que es el correlato necesario de la verdad como "entre". Lo que acontece en principio entre la obra de arte y el hombre es una relación semántico-existencial, donde lo que prima es el ser/significado alzado como mundo, que a su vez no se agota en su manifestación contingente, sino que permanece como abismo de reserva ("tierra”) para futuras donaciones de sentido. La obra de arte conlleva entonces una revelación ontológica que muestra en plenitud cómo es el ser y de qué manera este deviene como tal para el hombre.

Por este motivo es que la poesía, en tanto esencia del arte, es fundación del ser (y no creación del ente): Heidegger nos aventura el sentido del ser, que es "aquello qué y cómo el ente nos es siempre a la vez abierto y oculto" (p. 19), es decir, el mundo como espacio semántico de la alétheia. Esta fundación refiere a tres aspectos unidos entre sí: donación, fundación, e inicio. Si bien el Dasein se encuentra en una posición pasiva, a su vez puede pensarse esta donación como articulada con el proyecto poético, pero también con el proyecto tal como es desarrollado en SuZ, en tanto "el proyecto poético es lanzado al Da-sein histórico". En efecto, el comprender es un existenciario clave del Dasein, articulado a la vez por la disposición afectiva y por el lenguaje; el "estado de abierto" del comprender abarca el "por mor de qué" y la significatividad, es decir, abarca el ser en tanto existir. El Dasein es esencialmente su posibilidad, aquello que puede ser en el horizonte de su proyecto comprensivo: es "posibilidad yecta", posibilidad de ser libre para ganarse o perderse, responsable de sí mismo. Este comprender tiene a su vez la estructura existenciaria de la proyección, que proyecta el ser del "ser-ahi" originariamente sobre la significatividad/mundanidad de su respectivo mundo: "el comprender es, en cuanto proyectar, la

\footnotetext{
${ }^{10}$ Generalmente se suele traducir por "acontecimiento"; sin embargo, en tanto posee la raíz del eigen, tiene también el sentido de -propiación -Como señala Rebok, puede usarse tanto "a-propiación" como "ex-propiación"- (Rebok, s.d.). La conexión "(de)" remite a la estructura sartreana de la intencionalidad, donde cabe pensar una diferenciación, pero sólo desde una instancia ontológica-fenomenológica y no fáctica.
} 
forma de ser del 'ser-ahi' en que éste es sus posibilidades en cuanto posibilidades" (Heidegger, 2014, p. 163). Y, a su vez, el "estado de abierto" del ser en general está inserto en este "estado de proyectado".

Es desde aquí que puede pensarse el modo en que el arte necesita al hombre para ser y, más concretamente, cómo es que la verdad abierta por la obra inhiere en la existencia misma del Dasein histórico. Como agrega Heidegger en su apéndice a la edición de 1949, el arte es pensado como Ereignis; desde él, el ser es una llamada hecha al hombre, y el ser abierto mismo no puede ser sin ellos:

[...] es dentro de la relación humana con el arte donde se da la segunda ambigüedad del poner a la obra de la verdad, que en la página 51 es nombrada como creación y cuidado [...]. En la frase 'poner en obra la verdad' [...] se esconde la relación del ser y la esencia del hombre (Heidegger, 1935, p. 62).

Hay que analizar ahora de qué manera la relación estética con el arte trae en sí la decisión fundamental por la verdad del ser, donde se juega no sólo el destino de este sino la posibilidad de la propiedad o impropiedad de la misma existencia del Dasein.

\section{Relaciones hermenéutico-significativas entre Dasein y obra de arte}

En tanto que poner a la obra de la verdad, el arte es poema. No es sólo la creación de la obra la que es poética, sino también, aunque de otra manera, el cuidado de la obra. En efecto, una obra sólo es efectivamente real como obra cuando nos desprendemos de nuestros hábitos y nos adentramos en aquello abierto por la obra para que nuestra propia esencia pueda establecerse en la verdad de lo ente (p. 54).

Destacamos tres ideas fundamentales que orientarán en adelante el desarrollo del trabajo: por un lado, la doble modalidad que el Dasein puede asumir en relación a la experiencia significativa con la obra de arte; por otra parte, a pesar de la "pasividad" de éste en el alzamiento del mundo, veremos cómo su pasividad es de algún modo activa para que acontezca la verdad en la obra; finalmente, 
veremos de qué manera la esencia del Dasein se ve revolucionada en el compromiso acaecido por la transpropiación de sentido dado en la experiencia estética y cómo se articula con el cuidado de su autenticidad existencial.

Ya desde el comienzo Heidegger muestra que, si bien la obra surge "a partir y por medio de la actividad del artista", éste a su vez es "originado" por la obra; y ambos, a su vez, tienen su origen en un tercer elemento, que es el arte. La maniobra de Heidegger es quitarle todo tipo de subjetivismo fuerte a la concepción de la creación artística, ya que lo que prima no es tanto la motivación psicológica del artista o el que la obra sea testimonio de genio y grandeza, sino que debe entenderse que en la obra aconteció el desocultamiento de lo ente y que esto permanece en sí mismo con autonomía respecto del acto particular de creación. Esto no implica desconocer por completo al artista, sino comprender que el ser abierto por la obra lo trasciende más allá de sus intenciones iniciales:

[...] ese acontecimiento que consiste en que la obra haya sido creada no se limita a seguir vibrando en la obra, sino que es el mismo acontecimiento de que la obra sea como tal obra el que proyecta a ésta ante sí misma y la mantiene proyectada en torno a sí. (p. 47).

Por otra parte, cabe recordar que en tanto obra ésta es lucha entre mundo y tierra, y es precisamente en medio de esa lucha donde es arrojado el Dasein en su presencia. Heidegger señala que cuanto más esencialmente el mundo de la obra emerge y se destaca, al mismo tiempo la obra se vuelve más oscura y extraña en su esencial cerrarse, al punto que parece "cortar todos los vínculos con los hombres". Sin embargo, esto es lo que posibilita nuestra introducción en el seno de la lucha interna de la obra, nuestro ingreso a participar de este pólemos semiótico, ya que nos fuerza a salirnos de lo habitual (y por ende de nuestra constante proyección y determinación de la objetividad de las cosas) para demorarnos en el ser de la obra. Esta prestada "función poética del lenguaje" que análogamente vemos como efecto de la obra, transforma nuestras relaciones habituales con el mundo y la tierra y permite así "dejar que la obra sea una obra": esto es lo que Heidegger denomina "cuidado (Bewahren) por la obra", y que es la clave para pensar la experiencia 
estética. Este dejar-ser es la actitud fundamental de la fenomenología (propiamente heideggeriana), y gracias a ésta es que "la obra se da en su ser creación como aquello efectivamente real", es decir, puede permanecer en sí como lucha significativa.

Tomando cualquier ejemplo, algún lienzo de Van Gogh ${ }^{11}$ o el Guernica de Picasso, lo que acontece en ese cuadro gigantesco por sí mismo en tanto obra, es la apertura de un plexo de significaciones, un mundo, a partir de una composición que no agota esa verdad particular; generaciones posteriores, o incluso uno mismo en otra vuelta, puede recibir sentidos diferentes, que variarán también de acuerdo a cuánto dejemos que la obra sea y no que seamos nosotros los que forcemos ver un significado o "símbolo" determinado en el lienzo. Este dejar-ser, además, nos mueve a demorarnos en el cuadro y participar nosotros de ese pólemos, ya que la tierra de éste nos resulta de algún modo inabarcable y fundamentalmente inagotable, y se nos resistirá a ser insertado en una articulación segura e inmutable de referencias; y cuando creamos haber "comprendido" definitivamente todos los elementos de la imagen, siempre habrá posibles nuevas interpretaciones y aperturas que descoloquen nuestro propio mundo. Por eso en la primera versión de El origen de la obra de arte Heidegger afirma con razón que "la relación con el público, ahí donde lo hay, es solamente que este es destruido por la obra" (1931 p. 8), en el sentido de que el mundo del Dasein sufre una "deconstrucción" (con todas las licencias que nos permitimos en su uso), en tanto el combate significativo afecta las diversas capas de sentido que el Dasein de algún modo es. En esta fuerza destructiva, dice Heidegger, se mide la grandeza de una obra de arte.

El cuidado como dejar-ser es tan esencial a la obra como su ser-creada; en efecto, "en la misma medida en que una obra no puede ser sin haber sido creada pues tiene necesidad esencial de creadores, tampoco lo creado mismo puede seguir siendo sin sus cuidadores" (1935, p. 48). De esta manera, si bien la iniciativa de fundación de sentido reside en el ser de la obra, se ve claramente que el Dasein no es en absoluto prescindible, en tanto sin Dasein no hay ser alguno que abrir; "si realmente es una obra, siempre guarda relación con los cuidadores", aun cuando los espere para su ingreso en su verdad. Sin embargo, el olvido de la obra es también un modo del

\footnotetext{
11 Incluso, el de los zapatos.
} 
cuidar; la obra no se reduce a la nada, sino que permanece latente a la espera del Ereignis. Lo mismo ocurre con el ser, que en su historia ha sufrido el olvido y abandono del hombre, aunque quizás sea más bien que fue el hombre el olvidado y abandonado por el ser.

Los cuidadores son ciertamente figuras del Dasein auténtico, que corresponden al llamado del ser tal como se da en su verdad en la obra; es cada uno de nosotros en la medida en que nos apropiamos del sentido fundado en cada caso. Cuidar la obra implica "mantenerse en el interior de la apertura de lo ente acaecida en la obra" (1935, p. 49), y que Heidegger piensa como una suerte de saber, claramente no representativo-objetivante, sino un saber sobre el ser, saber lo que se quiere en medio de lo ente. Éste saber-querer

[...] es el sumirse extático del hombre existente en el desocultamiento del ser [...]. Querer es la lúcida resolución ${ }^{12}$ de un ir más allá de sí mismo en la existencia que se expone a la apertura de lo ente que aparece en la obra [...]. El cuidado por la obra es, como saber, el lúcido internarse en lo inseguro de la verdad que acontece en la obra (p. 49).

Como se ve, la inseguridad de la obra es la posibilidad del in-mundo, el riesgo de caer en lo alosemiótico; de ahí que la resolución del Dasein, en tanto proyectarse a la angustia, juegue un rol fundamental en la proyección del mundo abierto por la obra, ya que a su vez el acontecimiento de verdad está fundado sobre el abismo de la nada ${ }^{13}$, es decir, de la diferencia. Ahí, el hombre es arrojado, ex-tático, al claro de la verdad, que a su vez es noche silenciosa y abismal de la tierra. Y, sin embargo, en la dificultad que implica apropiarse del sentido, es posible para el Dasein participar del pólemos y comprender-interpretar lo proyectante de la obra en su propio proyecto hermenéutico. Por eso es que "el cuidado de la obra no aísla a los hombres en sus vivencias" estético-psicológicas, sino que (además) los adentra en la pertenencia a la verdad del ser que

\footnotetext{
12 En el sentido de "estado de resuelto" tal como aparece en SuZ.

13 "¿Quiere decir esto que la verdad surge de la nada? Efectivamente, si entendemos por nada la mera nada de lo ente [la diferencia ontológica] y si nos representamos a ese ente como aquello presente corrientemente y que debido a la instancia de la obra aparece y se desmorona como ese ente que sólo pretendidamente es verdadero" (p. 52)
} 
acontece en la obra de arte y así "funda el ser para los otros y con los otros como exposición histórica del ser-aquí a partir de su relación con el desocultamiento" (p. 52).

De esta manera, el arte funda también la historia de un pueblo histórico, y por eso la poesía es el proto-lenguaje que configura la historia del ser. El arte en tanto origen de la obra es lo que hace que surjan a su vez los creadores y los cuidadores, como reclamados por el ser para la guarda14 de su verdad. El proyecto poético instaurado por la obra, que viene de la "nada" (es decir, del ser como diferencia, no de lo corriente [el ente]), es a su vez la propia determinación oculta del Dasein histórico, verdadero agente que soporta la experiencia estética. En el proyecto verdaderamente poético la tierra se transforma en patria y el mundo en lo que reina desde el desocultamiento del ser; así se funda el fundamento que soporta el claro, y en tanto retiene y acentúa la lucha en su intimidad, es así “el resistir creador en el abismo” (Heidegger, 2011, §13).

\section{Consideraciones finales}

A lo largo de este trabajo hemos intentado reconstruir, desde una perspectiva semiótica, los argumentos desarrollados en El origen de la obra de arte que nos permiten entrever la manera en que el Dasein se relaciona con la obra. El modelo de función significante de Greimas puede ayudar a pensar esta lucha esencial que se da frente a todo signo y que se mantiene naturalmente en la obra de arte; en efecto, en la práctica cotidiana (el "negocio" del arte), uno contempla obras de todo tipo, en lugares diversos, y generalmente busca encontrar en las obras significados; sin embargo, la mayor parte de las veces, si bien puede encontrarse algún tipo de sentido, pareciera que las obras "guardan para sí" su propio mundo, como encerrándose en su propia materialidad inmanente, lo que las vuelve oscuras y demandantes de una demora de parte del contemplador, demandantes de tiempo para que ellas puedan ser. Esta dificultad propia de toda gran obra (que no significa que no pueda aplicarse al arte contemporáneo, el arte de masas) provoca dos posturas básicas; o la proyección subjetiva y de algún modo forzada de las propias vivencias que produce la imaginación,

\footnotetext{
${ }^{14}$ Cabría remitirse a la Carta sobre el 'humanismo' (Heidegger, 2001) y todo su desarrollo del schonen del ser, que convierte al hombre en su "Pastor"; la prefiguración del "pensador esencial" en notable.
} 
lo que es otra forma de "habladuría" en tanto uno no resiste la inefabilidad, el silencio que la obra es en sí misma por ser el lenguaje un misterio; o la proyección de un mundo que abre un horizonte de sentido en tanto acontecimiento de una verdad, en la medida en que uno, demorándose, cuida la obra para que esta sea. En este último caso, como ya vimos, el arte es un Ereignis ${ }^{15}$ en tanto acontecimiento que abre un espacio semiótico donde el Dasein se apropia hermenéuticamente del sentido proyectado por el mundo de la obra, a la vez que es apropiado por este mismo sentido. En el fondo, puede pensarse desde Sartre que la experiencia estética será auténtica en la medida en que haya un compromiso entre hombre y obra. Este compromiso, como meterse-en-con, implica una transformación de la propia existencia, en la medida en que la existencia del Dasein no es sino la propia comprensión de su ser, articulada con su Stimmung y el lenguaje: es cura, ocupación en su ser-relativamente-a-la-muerte, proyecto-yecto, que debe apropiarse de su existencia para ganarla entonces para sí. Esta apropiación es la otra cara del Ereignis, que es de esta manera esencialmente acontecimiento de transpropiación [de sentido].

Lo que el hombre deviene existiendo en relación al ser es ser auténtico, es decir, habitar "poéticamente" la tierra procurando para su pueblo la apertura de horizontes de sentido diversos, construyendo la "casa del ser" que es el lenguaje en donde acontece todo ente, para llevar a la palabra al ente en su origen. En otros textos posteriores, las figuras que encarnan el Dasein auténtico son los pensadores y los poetas esenciales; los primeros piensan el ser en cuanto tal, y así descienden hasta su profundidad abismal; los otros nombran lo sagrado, alzándose hasta el "cielo" del mundo, activando el sentido para un pueblo. El lenguaje, "en tanto conversión del ser en palabra, se hizo poesía. La lengua es la proto-poesía en la que un pueblo poetiza el ser" (Heidegger, 2003, p. 156), y a la inversa. La poesía en este sentido amplio, es la esencia del arte, y en cuanto tal es que funda la historia. No debemos olvidarnos del carácter acontecial-epocal de ésta, en tanto el mismo ser es evento. Tampoco, considerar que la obra de arte sea el único origen de la verdad y del sentido. Sin embargo, en sus anotaciones marginales a la primera versión de El origen de la obra de

\footnotetext{
15 Podemos arriesgar incluso la idea de que el arte, en tanto Ereignis, tiene su origen en la experiencia estética [auténtica].
} 
arte, Heidegger escribe: “El arte, un origen de la verdad. Forma fundamental de su devenir. El arte es historia. Acción y pensar. Alcanzar saltando" (1931, p. 23). El arte es uno de los tantos modos que tiene la verdad para acontecer; y sin embargo, en tanto forma fundamental del devenir, es modelo clave del Ereignis y de la forma en que el sentido se da. El modelo "antropológico" que aún persistía en SuZ da paso a un modelo "ontológico" donde las cosas, y especialmente la obra de arte, son las que organizan el espacio semántico donde el hombre habita. Este espacio limitado, por fuera del cual no hay posibilidad de ente [inteligible], sólo puede ser alcanzado por medio de un salto; este salto es la decisión de hacerse cargo del ser, hacerse cargo de la propia existencia, hacerse cargo de la obra mediante su cuidado.

Desde estas caracterizaciones fenomenológico-hermenéuticas es que podemos pensar la experiencia estética como una relación semántico-existencial, donde no se pierde la aísthesis (como se le ha criticado largamente a Heidegger) sino que ésta es reconocida como instancia articulada por el lenguaje comprendido, donde lo que prima es la significatividad contingente de la obra. Sólo reconociendo este sentido en que alguna verdad acontece es que podremos establecer con el arte y con la propia humanidad histórica una verdadera relación de cuidado, enlazados esencialmente con el llamado del ser, existiendo así más auténtica y poéticamente.

\section{Referencias}

Bertorello, A. (2008). El límite del lenguaje. La filosofía de Heidegger como teoría de la enunciación, Buenos Aires, Biblos.

Heidegger, M. (2014). El ser y el tiempo, trad. de Gaos, J., Buenos Aires, FCE.

Heidegger, M. (2012). “El origen de la obra de arte” en Caminos de Bosque, trad. de Cortés, H. y Leyte, A., Madrid, Alianza.

Heidegger, M. (2011). Aportes a la filosofía: acerca del evento, trad. de Picotti, D., Buenos Aires, Biblos.

Heidegger, M. (2003). Introducción a la metafísica, trad. de Ackermann Pilári, A., Barcelona, Ed. Gedisa. 
Heidegger, M. (2001). “Carta sobre el 'humanismo'” en Hitos, trad. de Cortés, H. y Leyte, A., Madrid, Alianza Editorial.

Heidegger, M. (1935). El origen de la obra de arte. [Versión electrónica]. http://www.lauragonzalez.com/TC/Heidegger El origen de la obra de arte.pdf

Heidegger, M. (1931). El origen de la obra de arte (primera versión), trad. de Ángel Xolocotzi en Revista de Filosofía (115).

Rebok, M. G. (s.d.). Hölderlin y Heidegger, un retorno de la disposición hacia lo sagrado: poesía y pensamiento. [Versión digital] http://proyectohermeneutica.sociales.uba.ar/wpcontent/uploads/sites/31/2016/12/mg rebok.pdf 